\title{
A conversação no contexto das relações assimétricas no trabalho organizado
}

\author{
Juan Adolfo Brandt ${ }^{\mathrm{I}, 1}$ e Aílton Amélio da Silva ${ }^{\mathrm{II}, 2}$ \\ ${ }^{\mathrm{I}}$ Universidade Bandeirante do Brasil \\ II Instituto de Psicologia da Universidade de São Paulo
}

\begin{abstract}
Neste artigo desenvolvemos considerações a respeito da conversação entre ocupantes de cargos de liderança e os seus subordinados na linha hierárquica, dentro das organizações do trabalho. Inicialmente apresentamos algumas conclusões que obtivemos a respeito das relações assimétricas no trabalho organizado mediante a análise dos conteúdos que foram trabalhados em pesquisas envolvendo grupos de supervisores de equipe. Realizamos ainda um debate sobre o campo teórico da conversação, focalizando sua especificidade no trabalho organizado. Para facilitar a compreensão dos temas que colocamos em debate, incluímos também a análise de algumas cenas de um filme que trata do cotidiano das organizações empresariais. Finalmente, chegamos a conclusões relevantes para a ampliação da compreensão das dificuldades presentes na conversação entre líderes e subordinados, ao debatermos sobre a repercussão que ocorre nessas situações quando temos simultaneamente a assimetria na relação e a perda da confiabilidade do líder.
\end{abstract}

Palavras-chave: Liderança, Organizações, Relações assimétricas, Análise da conversação, Grupos.

The conversation of asymmetric relations in an organized work context

In this article we have developed considerations regarding the conversation among the holders of leadership positions and their subordinate in the hierarchical line, within the work organizations. Initially we presented some conclusions which we have obtained regarding the asymmetric relations in an organized work by means of the contents analysis that were elaborated in researches involving team leaders groups. And we also performed a discussion about the theorist field of conversation, with focus in its specificity in the organized work. To make easy the comprehension of the themes which we placed in discussion, we have also included an analysis of some scenes of a movie that deals with the day to day at entrepreneurial organizations. Finally, we came to some applicable conclusions for the enlargement of difficulties comprehension present in the conversation among team leaders and subordinates, when we have discussed about the reverberation which occurs in these situations when we have the asymmetry in relation and the leaders reliability loss, simultaneously.

Keywords: Leadership, Organizations, Asymmetric relations, Conversation analysis, Groups.

\section{Introdução}

$\mathrm{E}_{\mathrm{p} s \mathrm{sen}}$ ste artigo contempla a análise de aspectos que estão presentes nas conversações entre as - pessoas que ocupam as posições de comando ${ }^{3}$ no trabalho organizado e as pessoas subordinadas a elas. São aspectos das relações humanas que se referem ao tema da liderança e perturbam os relacionamentos entre essas pessoas, afastando-as; ao mesmo tempo, interferem no propósito dos líderes de obter bons relacionamentos com os subordinados devido à necessidade de que seja obtido o máximo desempenho deles, afetando o seu sucesso.

\footnotetext{
1 Doutor em Psicologia Social pelo Instituto de Psicologia da Universidade de São Paulo. Professor de Psicologia do Trabalho e Psicologia Organizacional na Universidade Bandeirante do Brasil.

2 Professor do Departamento de Psicologia Experimental do Instituto de Psicologia da Universidade de São Paulo.

3 Para referir-nos às pessoas que ocupam cargos de comando nas organizações usamos neste artigo essa mesma expressão, bem como as seguintes: líderes, líderes de equipe, líderes formais, supervisores, chefes, figuras de autoridade.
} 
Entretanto, não incluímos nesta análise a liderança como conceito ou conjunto de características desejáveis para o sucesso do negócio. Concentramos a nossa análise no campo das relações humanas, procurando reconhecer como se dão os encontros conversacionais entre as pessoas, independentemente das considerações que possam sustentar o debate teórico sobre liderança.

A nossa análise focaliza o campo que denominamos "Relações Assimétricas", mas reconhecemos que isso implica em colocarmos constantemente em referência a crítica às atuações dos líderes formais em organizações de trabalho quando se dirigem aos seus subordinados.

Esclarecemos que estamos adotando o termo "relações assimétricas" para nos referirmos às relações humanas entre duas ou mais pessoas, que se apresentam dissimétricas ou não-simétricas no que se refere ao poder que é disponibilizado a cada uma delas para atuar na própria relação. Nessas relações, uma instância superior estabelece e concede objetivamente e formalmente a uma das pessoas o poder de determinar o que a outra ou as outras devem pensar, controlar, fazer ou deixar de fazer; portanto está presente uma linha de subordinação entre elas. As relações assimétricas são próprias do trabalho organizado.

Ressaltamos que, tendo faltado às disciplinas interessadas em estudar o tema da liderança a necessária autonomia quando atuaram no âmbito de sistemas organizacionais, essas disciplinas passaram a priorizar os estudos que focalizaram contribuições para atender à premência do sistema por maximização da produtividade; assim tiveram que assumir posições desconfortáveis em relação aos trabalhadores. Essa condição foi típica da psicologia organizacional. Dessa forma, tornaram-se recorrentes os estudos e intervenções que focalizaram o propósito de "extrair o máximo das pessoas". A leitura de Malvezzi (1999) elucida diversos aspectos sobre essa história de contradições.

Consideramos que essa opção em privilegiar a maximização da produtividade induz os líderes formais a estabelecer relações extremamente utilitárias com os seus subordinados e que essa condição interfere de um modo negativo nos encontros conversacionais entre eles.

\section{Considerações iniciais a respeito das relações assimétricas no trabalho organizado}

Há condições de poder próprias das organizações do trabalho que interferem nas relações entre os trabalhadores e seus superiores hierárquicos de modo a provocar um distanciamento importante entre eles. Esse sistema está fundamentado na hierarquia e na divisão do poder; lembramos que o poder é essencial para sustentar o funcionamento dessa divisão e o cumprimento de metas que devem assegurar o sucesso do empreendimento.

As organizações do trabalho impõem aos seus empregados que eles ocupem posições de heteronomia ${ }^{4}$; isso ocorre mesmo quando, pelo cargo ocupado, poderia ser esperado que tivessem um grau razoável de autonomia. Assim, são verificadas diversas ocorrências indicativas de um atravessamento de fatores relacionados com essa heteronomia na forma das relações e das conversas.

Enriquez (1991) afirma, entre diversas argumentações e questionamentos: "Não existe líder sem homem sedutor e repressor; nem divisão do trabalho sem pessoas dominantes que têm o direito de pensar e exprimir sua palavra e sem pessoas submissas, mantidas à distância de seus

4 O termo heteronomia é utilizado para significar a condição da pessoa ou de grupo que receba de um elemento que lhe é exterior, ou de um princípio estranho à razão, a lei a que se deve submeter. Dicionário Aurélio. O termo é aplicado aqui para significar a falta de autonomia. 
desejos e de suas palavras" (p. 17). Em outra obra, esse mesmo autor (Enriquez, 1997) apresenta um pensamento que complementa a afirmação anterior:

As organizações [...] mesmo aquelas que adotaram uma estrutura estratégica e, portanto, exigem de seus membros entusiasmo e a iniciativa têm tendência a integrar os indivíduos heterônomos e a desconfiar dos sujeitos autônomos. O primado atual do indivíduo é o primado do indivíduo conformado, massificado, ou ainda do homem que adota uma identidade coletiva forte, que é dominado pelo narcisismo individual e pelo narcisismo grupal ou organizacional (pp. 121-122).

Ao mesmo tempo, temos implicações nas relações assimétricas que decorrem do intenso uso dos seguintes verbos: "mandar, obedecer, fazer e controlar" ou de ações que têm essas conotações. Essas implicações podem ser complexas, pois o grau de exigência ou necessidade que é traduzida por esses verbos pretende constituir as bases que permitem assegurar o resultado do sistema.

Entretanto, existem outros aspectos que devemos levar em consideração, pois não é somente o trabalho em sua condição de organizado, característica essencial do sistema, que condiciona as relações. Estão presentes outros fatores que podem ser analisados a partir de uma leitura de aspectos subjetivos e intersubjetivos que afetam essas relações.

Brandt (2006) teceu considerações a respeito de fatores subjetivos e intersubjetivos presentes nas relações assimétricas. Esse trabalho foi fundamentado no pensamento de Kaës (1997) a respeito de alianças inconscientes. Segundo esse último autor, o vínculo se organiza a partir de conteúdos que devem ser negados para que a aliança possa existir. Assim, surgem os pactos denegativos e os contratos narcísicos como elementos fundadores do grupo. Algo precisa ser negado para que possa ser viabilizada a coexistência no grupo. No mesmo texto de Brandt a que foi feita referência anteriormente, encontra-se o pensamento de Enriquez (1997), no qual esse autor propõe que a análise adequada do sistema organizacional requer observações de fenômenos que muitas vezes são desconsiderados como, por exemplo, o simbólico, o cultural e o imaginário, bem como requer a análise de diversos aspectos da subjetividade. Finalmente, Brandt faz referência à análise dos processos grupais verificados em uma série de experiências com grupos de uma empresa. Os participantes pertenciam a níveis hierárquicos distintos, aspecto esse que teve influência importante para diversas consequências conflituosas e permitiu compreender aspectos presentes nas relações assimétricas.

Mais tarde, Brandt e Oliveira (no prelo) desenvolveram pesquisas com pessoas que ocupam cargos de supervisão. Aplicaram uma variação da modalidade de intervenção por meio de grupos, que foi desenvolvida por Balint (2005) durante os anos 1950, quando pesquisou as relações entre o médico e seu paciente. Essa modalidade de trabalho com grupos foi ajustada para permitir a análise das relações próprias dos ambientes de empresas e instituições públicas, dos líderes formais com os seus subordinados.

Esclareceremos os fundamentos dessa modalidade de intervenção grupal. É propiciada a análise em associação livre de palavras, centrada nos conceitos de transferência propostos por Balint. Esse pensador propôs que a transferência pode ser trabalhada de modo diferenciado, de acordo com os conteúdos que se apresentam. Segundo ele, existem conteúdos que são próprios e comuns a um campo profissional, que permitem trabalhar o que ele denominou transferência pública; ou seja, somente são trabalhados os conteúdos relacionados com a atividade profissional comum ao grupo. Os conteúdos subjetivos que remetem a aspectos pessoais, ou individuais dos participantes, são mantidos fora do campo de interesse nas intervenções do analista; esses conteúdos subjetivos foram conceituados como pertencentes ao campo da transferência privada.

Os participantes dos grupos da pesquisa coordenada por Brandt e Oliveira, todos ocupantes de cargos de comando, relataram casos de sua experiência pessoal envolvendo as 
suas relações com seus subordinados. Feito um relato por um dos participantes, o grupo se dedicava à sua análise, o que incluiu, por exemplo, ocorrências, sentimentos, dificuldades, razões de ser, motivações, frustrações, propósitos, opções de atuação, isto é, o conjunto de aspectos organizacionais, institucionais, subjetivos e intersubjetivos que podiam ser percebidos. Essas pesquisas envolvendo grupos de supervisores foram realizadas na Universidade, um ambiente externo às organizações.

Mediante esse estudo, verificamos um aspecto importante a respeito das relações assimétricas, que contribui para o distanciamento entre os interlocutores. Trata-se de dificuldades para estabelecer conversações quando existem questões que esses profissionais não conseguem abordar. Verificamos na análise dos conteúdos desses grupos que a carga emocional presente na conversação entre líder e subordinados pode ser elevada. Em diversas situações, quando devem conversar durante os encontros com subordinados, não conseguem encontrar o equilíbrio emocional adequado; isto porque estão presentes certas condições subjetivas, intersubjetivas, organizacionais ou institucionais que não favorecem esse tipo de equilíbrio.

Outro ponto importante a considerar refere-se à dificuldade desses líderes em atuar nas relações de acordo com os modelos propostos de liderança. Apresentam dificuldades em lidar com os aspectos próprios das organizações quando estas lhes impõem uma atuação fundamentada na manipulação dos subordinados. Ao mesmo tempo em que não se reconhecem como manipuladores, sentem-se cobrados no sentido de provocar motivação em suas equipes e terminam por atuar usando procedimentos de manipulação. Mas negam que isso tenha características negativas. Verificamos que essa condição faz com que eles percam a confiança dos subordinados.

Somente quando a equipe se mostra motivada e comprometida com as metas é que o responsável pela equipe consegue "sentir-se em equilíbrio". Mas, como motivar os subordinados e fazer com que sejam comprometidos, se eles questionam, ou não cumprem o que é necessário, ou insistem em apresentar pedidos cujo atendimento é inviável, ou ainda, se existem os segredos? Além disso, também estão presentes as políticas das organizações, que impõem "filtros" à informação.

Provavelmente, como consequência dessas condições, os líderes adotam estratagemas para evitar a conversa e fugir de conteúdos incômodos. Obtivemos relatos indicativos dessas condições nos grupos analisados: situações em que esses profissionais negam algo que sabem ser verdadeiro ou dizem algo que não corresponde à verdade ou ainda, em que evitam o diálogo efetivo. Disso decorre a elevada incidência de monólogos disfarçados e conversas evasivas que perpetuam o problema.

Também consideramos relevante a constatação de que os participantes que ocupam cargos de liderança não têm disponibilidade para interlocuções de longa duração. A dinâmica organizacional é tremendamente afetada pela competitividade e muitos desses profissionais não conseguem dispor de tempo suficiente para se dedicar aos subordinados.

\section{A análise da conversação}

Os conhecimentos que foram adquiridos durante as pesquisas que relatamos esclarecem aspectos relacionados às dificuldades que se apresentam nos processos de liderança. Porém, consideramos que devemos incluir na análise o estudo da conversação para enriquecermos o debate, incluindo, por um lado, certos aspectos gerais próprios de qualquer encontro conversacional e, por outro lado, os aspectos específicos desse ambiente de trabalho, que afetam de modo negativo a possibilidade de estabelecer-se o diálogo. 
Recorrendo aos pensadores do campo da conversação, encontramos em Ribeiro e Garcez (2002) a seguinte afirmação: "Susan Philips é uma das pioneiras em assinalar a importância da participação do ouvinte na coconstrução da conversa e da interação face a face. $\mathrm{O}$ interesse deixa de estar centrado apenas no falante para recair na figura do interlocutor que é ratificado pelo falante" (p. 21). Ressaltamos aqui essa afirmação por entendermos que a questão do reconhecimento do outro como sujeito que interage na conversa representa um dos pontos fundamentais na abordagem da conversação no trabalho organizado, na medida em que lá temos os monólogos dos supervisores disfarçados em conversa.

Philips (2002) aponta a importância das variáveis culturais presentes na interação face a face; isso a partir da comparação entre a população branca norte-americana e populações indígenas. Essa pesquisadora comprova a constante presença nas conversas, de diversas manifestações de caráter verbal e não-verbal realizadas por parte dos ouvintes, as quais funcionam no sentido de encadear essas interlocuções, sinalizando ao falante a sua continuidade. Esses encadeamentos contribuem para a estrutura sequencial da interação e a ordenação da fala.

Essas conclusões de Philips também contribuem para a compreensão do que ocorre no trabalho. Se o falante é o supervisor, pode ocorrer que ele não dê a devida importância aos sinais não-verbais e mesmo verbais apresentados pelo ouvinte que ocupa um cargo subordinado. Dessa forma, a estrutura sequencial da interação e a ordenação da fala são afetadas e ocorrem monólogos disfarçados em conversas.

Um conceito importante é a troca de turno. É essa troca que oferece aos interlocutores as oportunidades de falar e de ouvir. As trocas de turno (Marcuschi, 2006, pp. 19-33), quando envolvem pessoas que ocupam cargos desnivelados em termos de hierarquia, servem também como forma de assegurar que a relação rigidamente assimétrica está sendo mantida. Poderíamos incluir afirmações do seguinte tipo feitas por um subordinado quando ocupa o turno na conversa: "Sim, estou entendo", ou "Ok, vou correr atrás", ou ainda, "Sim, vou melhorar..." etc. Constituem reações ao que foi dito e de reguladores do fluxo da fala que garantem a continuidade da conversa. Os exemplos que fornecemos demonstram que em uma relação assimétrica é esperado que o interlocutor ocupante de uma posição subalterna confirme haver compreendido o que lhe foi dito pela autoridade.

Goffman (2002) aponta várias razões necessárias para analisarmos a conversa em um contexto mais amplo, chegando a dar o título de "Situação negligenciada" à situação social que sustenta qualquer conversa. $O$ autor enfatiza que "A fala é socialmente organizada, não apenas em termos de quem fala para quem em que língua, mas também como um pequeno sistema de ações face a face que são mutuamente ratificadas e ritualmente governadas, em suma, um encontro social" (p. 19).

Brown e Levinson (1978) propuseram a existência de princípios universais que regem os encontros conversacionais que configurariam o campo da polidez; segundo eles, os interlocutores, ao falarem, usariam certos estratagemas e rituais de modo a viabilizar a aceitação pelo outro daquilo que pretendem dizer. Essa temática se configurou como um campo de pesquisa e desde então tem sido intenso o debate a respeito das particularidades da polidez. Esses debates giram em torno, por exemplo, das diferenças culturais e individuais, bem como da posição social dos interlocutores e ainda sobre a influência de fatores cognitivos. Encontramos em Watts, Ide e Ehlich (2005) um exaustivo levantamento a respeito desse tema.

Kerbrat-Orecchioni (2006, pp. 104-105) nos lembra do perigo da ilusão universalista, que poderia induzir a expectativa de que em todas as culturas estão presentes comportamentos verbais e não-verbais semelhantes e equivalentes. Os exemplos apontados por essa autora permitem remeter-nos a situações comuns do trabalho organizado. Nossas experiências em organizações e com grupos de profissionais que ocupam cargos de comando corroboram a elevada ocorrência de supostos universalistas aceitos como verdadeiros nesses ambientes, na 
medida em que os interlocutores não consideram a possibilidade do diferente. Em nome de uma racionalidade que é usada como argumento para padronizar o ambiente interno do trabalho, o ambiente externo também passa a ser visto como se fosse padronizado. Isso também acontece na forma com que as pessoas são "vistas", uma vez que existe uma expectativa sobre padrões de comportamento que elas devem atender. Decorre daí a possibilidade de que a ocorrência do diferente nas pessoas seja negada, o que também é facilitado pela contribuição do próprio sujeito que é negado, pois ele também não quer ser notado como diferente. Temos assim, uma interlocução que tem como princípio negar o que não interessa, a partir de uma racionalidade que deve nortear a vida no trabalho. Nesse caso, a conversa pode tornar-se um monólogo disfarçado em conversa ou uma conversa composta de evasivas.

Essa mesma autora procura investigar com mais profundidade os aspectos de afetação de face que vinham sendo analisados desde que E. Goffman começou a debater o conceito de face. Kerbrat-Orecchioni desenvolve na mesma obra (2006, pp. 84-92) importante análise a respeito de polidez negativa e polidez positiva, versando sobre estratagemas usados cotidianamente por aqueles que estão falando para proteger a própria face e a face daqueles que são destinatários da fala.

\title{
A conversação nas relações assimétricas no trabalho organizado
}

Nossa questão situa-se na busca de uma saída para as condições adversas que surgem nas relações no ambiente do trabalho organizado na medida em que o sistema organizacional entra como um interveniente privilegiado, acirrando a necessidade de uso de estratagemas conversacionais além do que já é esperado nas situações sociais comuns.

Nos grupos da pesquisa que estudamos obtivemos relatos de profissionais que ocupavam cargos de liderança sobre situações em que se viram compelidos a falsear a verdade, omitir informações, negar notícias que poderiam afetar negativamente o "clima da equipe" e apresentar afirmações que não poderiam sustentar-se à luz da verdade.

Em sua obra "Por que mentimos?" Smith (2005, pp. 141-162) investe na análise dos fundamentos biológicos e psicológicos da mentira. A partir de análise do comportamento animal, esse autor propõe que a mentira tem sua origem em funções importantes como alerta e proteção no grupo. Segundo ele, o sussurro entre alguns sujeitos dentro de um grupo poderia ser uma herança do mundo animal. Smith supõe que em situações de perigo o animal transmitiria informações de alerta de tal modo que fossem inaudíveis ao inimigo (Smith, 2005). Os animais desenvolveriam mecanismos eficientes para disfarçar a comunicação quando fosse necessário. Esse estudo sugere que, em decorrência, o ser humano é dotado dessa facilidade de disfarçar as informações quando há risco para ele.

\section{O mesmo autor afirma:}

\begin{abstract}
Eles (os mentirosos) são socialmente mais inteligentes. Conseguem perceber o que a outra pessoa quer ouvir, o que é pertinente contar naquela hora, têm sensibilidade para notar a vulnerabilidade alheia. São melhores manipuladores. Mas é preciso dizer que mentimos melhor quando não sabemos que estamos mentindo. Ou seja, quando enganamos a nós mesmos. A melhor mentira é contada por aquele que acredita no que está dizendo (Smith, 2006).
\end{abstract}

A esse respeito é interessante ler o trabalho de Gianneti (2005), no qual o autor analisa a tendência do ser humano de enganar a si mesmo. $\mathrm{O}$ autoengano permite à pessoa ter uma imagem adequada de si mesma para interagir com outras pessoas e, assim, manter ou melhorar 
a sua autoestima e obter satisfações e a aceitação dos outros. Poderíamos supor que o desenvolvimento da competência que habilita uma pessoa a enganar a si mesma contribui para deixá-la melhor preparada para enganar os outros. Portanto, um líder eficiente em usar estratagemas de manipulação poderia ser aquele que está convencido de que está certo, mesmo que não esteja.

Consideramos relevante um fenômeno extremamente comum no ambiente organizacional. Trata-se das conversas reservadas da qual fazem parte certos interlocutores privilegiados em função do poder de seus cargos. São conversas às quais a grande maioria das pessoas não tem acesso. Poderíamos assumir que quando estabelecem essas conversas esses sujeitos estão se protegendo como grupo? Nesse caso, quando estivessem com as pessoas que não participam do grupo privilegiado, deveriam negar o conteúdo dessas conversas sigilosas. Mas, como pode ser aceita a negação do conteúdo se esse outro grupo é sabedor de que ele existe? Portanto, é necessário mentir! Mas, como mentir? Conforme já dissemos, a melhor mentira é aquela em que o próprio mentiroso acredita. Porém, é provável que esse profissional detentor de cargo de comando saiba que está negando alguma coisa. Nesse caso, o autoengano não está presente; ao mesmo tempo o subordinado pode pensar: "peguei o chefe na mentira".

Por que o chefe pode "ser pego na mentira"? Trazemos inicialmente Corraze (1982). Esse autor apresenta exaustivo levantamento sobre aspectos da comunicação não-verbal que ocorrem quando há o encontro entre as pessoas. Trata-se de um levantamento dos resultados de pesquisas feitas por outros pesquisadores dessa área. Nessa obra o autor apresenta diversos tipos de comunicações não-verbais que ocorrem simultaneamente com a comunicação verbal e indicam emoções, compreensão, sentimentos ou sensações.

Corraze apresenta um inventário de expressões faciais que variam em função do contexto e das situações e faz também um levantamento importante de variações que envolvem o olhar. No conjunto que engloba a face, o sorriso e o olhar, torna-se possível encontrar dezenas de formas de expressão dos afetos e interesses. O mesmo autor analisa as posturas corporais tendo destacado a questão da simetria ou assimetria corpo - face - olhar durante a comunicação. Outra modalidade comunicativa abordada é a tátil: toques que variam em função de contexto, gênero e outros aspectos.

Esses estudos sobre a comunicação não-verbal indicam que um interlocutor se torna confiável na medida em que há coerência entre o seu discurso e o que o seu rosto ou todo o seu corpo está manifestando. Há situações em que uma pessoa diz coisas em que o seu interlocutor não acredita embora a fala tenha sido coerente. A sua percepção captou a assimetria e/ou certa incoerência entre o verbal e o não-verbal, embora não seja capaz de identificar qual foi essa assimetria que causou a desconfiança. Se não alcança essa coerência, o falante "é pego na mentira". Isso porque uma boa parte da conversa pode ser constituída por sinais sutis que são quase imperceptíveis para a consciência.

Corraze (1982) também analisa a questão do território, tão comum no mundo animal, que está relacionado à força do dominante e que se repete no ambiente humano. Traz o conceito de espaço pessoal que pode ser relacionado ao de poder. Ao entrarmos em contato com esse conceito, vislumbramos outro possível motivo para a dificuldade na conversa entre chefes e subordinados. Supomos que o líder, ao conversar com seu subordinado, está defendendo seu espaço pessoal com uma motivação intensa porque está temendo uma ameaça ao seu poder. Poderíamos identificar essa resposta como sendo decorrente de um exacerbado investimento narcísico desse profissional sobre o cargo gerencial por ele ocupado.

Knapp e Hall (1999) apresentam um sumário das principais pesquisas sobre os efeitos do ambiente na comunicação humana. Segundo eles, "O ambiente em que as pessoas se comunicam frequentemente contribui para o resultado final dos encontros. Tanto a frequência como o conteúdo de nossas mensagens é influenciado por vários aspectos do ambiente em que nos comunicamos" (p. 89). Em seguida afirmam: "Sugerimos seis bases perceptivas para 
examinar os ambientes: formal/informal, acolhedor/frio, público/privado, familiar/não familiar, constrangedor/livre e distante/próximo" (p. 90).

Algumas dessas bases propostas por esses autores são consideradas atualmente na arquitetura empresarial de muitas organizações, que procuram oferecer ambientes adequados aos seus empregados de acordo com o que podemos denominar "uma estética focalizada no que é visível", incluindo espaços, iluminação, decoração, limpeza, arrumação, espaços de convívio etc. Entretanto, essas providências não asseguram a eliminação das condições que perturbam os relacionamentos adequados entre chefes e subordinados. Ainda resta o envolvimento dos interlocutores em questões subjetivas. Pensamos que nem sempre a existência de um jardim cheio de rosas consegue eliminar emoções negativas; rosas com seu odor e beleza somente são valorizadas por quem as quer bem e mesmo isso não é garantia de que o bom sentimento em relação às rosas seja transferido às pessoas.

Quando uma relação contém em si mesma um fator de afastamento que é causado pela assimetria do poder, qualquer conversa entre os sujeitos dessa relação conterá aspectos contextuais que marcarão a interlocução. A esse respeito consideramos relevante a análise de Laing (1973) sobre os conceitos de "petrificação", "negação" e "desconfirmação existencial". Consideramos a possibilidade de um interlocutor com mais poder que o outro colocar marcadores na conversa que provocam o distanciamento entre os participantes, afastando de si aqueles que detêm pouco poder, de modo a conduzi-los para uma condição de "não existência". Dependendo da situação presente, podemos ter um monólogo disfarçado em conversa.

Precisamos manter controle sobre o processo conversacional a ponto de conseguirmos ser aceitos como desejamos e lidar com as possíveis dificuldades. A realização desse controle carece de estratégias, que implicam em um conjunto de ações que estabelecem os espaços de cada um dos sujeitos presentes na conversa. E. Goffman (1983) analisa as estratégias utilizadas para que os envolvidos em interações conversacionais consigam estabelecer os "espaços interacionais" adequados para cada um deles.

Smith (2006) complementa os apontamentos de Goffman. Esse autor apresenta o uso do ato de enganar como a fonte em que se sustenta toda a estratégia. Há a possibilidade de que o sujeito leve o ato de enganar tão longe que chegue ao autoengano, tornando-se mais convincente. Vimos anteriormente que Gianeti (2005) elucida esse aspecto. São necessários disfarces suficientemente convincentes, que possam ultrapassar a crítica realizada pelo outro sujeito da interação. Há disfarces que falham e precisam ser substituídos porque se torna visível a assimetria na relação; há outros disfarces que funcionam e a relação se mostra simétrica, em termos de coerência entre o que é emitido e o que é expresso.

Se um sujeito não tem suficientes oportunidades de enganar, ele fica limitado no campo estratégico da conversa. Em consequência, perde parte representativa de suas condições de controlar o encontro conversacional. Podemos supor também que permanece certa assimetria na conversa e repetimos: o sujeito perde a condição de existir em termos relacionais da forma que deseja.

Nesse ponto, o texto de Carducci (2002) sobre a timidez na vida adulta passa a ter sentido especial. Imaginemos essa conversa em que um sujeito está sendo impedido de enganar e imaginemos também que ele apresente as características do tímido, talvez porque a relação assimétrica o iniba. Esta é uma condição comum no ambiente do trabalho organizado. Os problemas de assimetria não são resolvidos e a conversa deixa de ter certas características necessárias para que se possa dizer que está havendo interação significativa.

As propostas de Carducci para resolver as inibições do tímido, podem não ser aplicáveis quando o sujeito está no ambiente de trabalho. Melhor, qualquer proposta que não leve em conta a necessidade de uma mudança nas relações de modo a permitir aos sujeitos da interação 
exercer controle sobre a conversa, não dará conta de criar as condições para a existência de conversas em relações que por si mesmas são assimétricas.

Qual é o engano proposto na interação? Aquele que permite ao sujeito a condição de existir, ou seja, que lhe permite formatar, pelo menos parcialmente, o relacionamento da forma que deseja. Este pode ser considerado como o objetivo maior da conversa ou um deles e é para tal que é usada a ação de enganar.

Ao discutir sobre a coerência conversacional, segundo a perspectiva de M. Coulthard, Marcuschi (2006) afirma: "parece que a conversação é comandada pelo princípio da parcimônia, que diz não ser conveniente falar aquilo que se supõe sabido pelo parceiro". Prosseguindo, "sabemos que algumas coisas são "conversáveis" e outras não" (p. 77).

A leitura desse trecho remete a cenas do trabalho em que se verifica a influência negativa dessa peculiaridade. Chefes que não conseguem falar aos subordinados com a devida clareza a respeito de fatores que estão afetando o desempenho ou a imagem deles e, quando ocorrem demissões, os trabalhadores demitidos demonstram surpresa. Isso é agravado por situações em que o chefe não mantém o princípio da cooperação, fala sozinho, mesmo quando existem os turnos de fala. Ressaltamos outro trecho da mesma obra (Marcuschi, 2006):

Tudo leva a crer que a categoria básica no processo inferencial seja a compreensão, já que ela permeia o processo em todos os momentos de sua realização. Mas a compreensão não é fruto do trabalho de um dos interlocutores apenas, e sim dinamicamente construída por vários, ao se considerar a bilateralidade dos atos conversacionais (...) (p. 84).

Torna-se fundamental que a conversação seja uma produção conjunta.

Isto permite que se tome a conversação como uma atividade de coprodução discursiva, mesmo quando a fonte é um indivíduo de cada vez. E é provavelmente neste movimento que se deve analisar o difícil problema dos processos argumentativos, em que os falantes estão engajados, transformando-se em coargumentativos.

\section{Apresentação da sequência de cenas de um filme que reproduz o ambiente presente nas organizações}

Para obtermos uma compreensão maior das implicações que decorrem de dificuldades em estabelecer conversas no ambiente das organizações quando está presente uma carga emocional de intensidade considerável, torna-se útil verificar as reações das pessoas envolvidas. Por isso optamos por apresentar ao leitor algumas cenas de um filme que retrata o ambiente corporativo, detalhando aspectos que debatemos até agora. .

Trata-se do filme francês Le placard (O closet) (2005), dirigido por Francis Veber. O nosso objetivo é identificar, no comportamento dos atores durante a trama, os elementos que compõem uma conversa, quando a carga emocional interfere de modo negativo na relação entre os interlocutores.

O filme conta a história de Pignon, um profissional (contador) que trabalha em uma organização e não tem o apreço dos demais trabalhadores e supervisores. Ele descobre, após ser discriminado num evento, que será demitido. Toma conhecimento disso porque surpreende uma conversa que ocorre no banheiro, envolvendo o chefe de pessoal e outra pessoa. Logo em seguida, esse contador se dirige à sua sala de trabalho e pergunta à sua chefa se ela sabia dessa demissão. Ela retruca negando o conhecimento disso, usando afirmações que negam e, ao mesmo tempo, traem suas palavras. 
Escolhemos essas cenas por serem emblemáticas do mundo corporativo, representativas de diversas situações que foram relatadas por participantes dos grupos da pesquisa realizada por Brandt e Oliveira (no prelo).

Focalizamos o detalhamento de uma sequência envolvendo três cenas curtas, em que temos o propósito de identificar e ilustrar importantes elementos de uma conversa que interferem na interação entre os interlocutores.

\section{Cena em $2 m 39 s$ do filme}

O filme inicia-se com uma cena em que toda a equipe de profissionais de uma empresa se posiciona sobre um conjunto de escadas para uma foto. A organização do grupo é feita de modo que é obedecida a hierarquia. O primeiro degrau é ocupado pelos trabalhadores de menor hierarquia e o último degrau, o mais alto, pela diretoria e presidência.

O fotógrafo não consegue enquadrar todas as pessoas do primeiro degrau e solicita a Pignon, que estava em uma das pontas da fileira, que se inclua no quadro. Isso é dificultado porque na ponta do lado contrário da fileira outro homem sai do enquadre da máquina fotográfica. Esse segundo personagem consegue reocupar um espaço no enquadre depois de empurrar a todos que estavam na mesma fila. Isso tirou novamente Pignon do enquadre.

O presidente da empresa fala: - Vamos tirar logo essa foto, sim?

O fotógrafo fala: - Ainda está fora o da gravata vermelha (Pignon).

O presidente volta a falar: - Vamos com isso! Já perdemos muito tempo.

Imediatamente Pignon se retira definitivamente do grupo que está sendo fotografado.

\section{Cena em $4 m 01 s$ do filme}

O fotógrafo e o chefe de pessoal estão no banheiro coletivo.

Chefe de pessoal: - Você bebeu ou o quê?

Fotógrafo: - Há 20 anos que faço isso e nunca tive problema de enquadre. Fiquei mal pelo da gravata (Pignon). Ele deve estar chateado.

Chefe de pessoal: - Tudo bem, ele vai ser demitido mês que vem.

Fotógrafo: - Sério?

Chefe de pessoal: - É, mas ele ainda não sabe. Está na lista negra.

Fotógrafo: - Coitado.

Chefe de pessoal: - Não, é um idiota.

Os dois se retiram do banheiro e aparece Pignon saindo de uma das cabines privativas do banheiro, de onde havia escutado toda a conversa entre o chefe de pessoal e o fotógrafo.

\section{Cena em $4 m 50$ s do filme}

A Srta. Bertrand (chefe de Pignon) e Ariane (colega de sala de Pignon) entram na sala de trabalho.

Ariane: - E eu fico?

Bertrand: - Sim, só ele vai ser demitido. 
Ariane: - Ele já sabe?

Bertrand: - Ainda não.

Ariane: - E por que vão demiti-lo?

Bertrand: - Redução de pessoal.

Ariane: - Que injustiça.

Bertrand: - É um bom contador. Tentei defendê-lo, mas...

Ariane: - Ele é legal, mas meio sem graça.

Bertrand: - Sim, mas é honesto, esforçado.

Ariane: - Sei, um chato.

Entra Pignon na sala:

Pignon: - Bom dia, Srta. Bertrand. Bom dia Ariane.

Bertrand: - Bom dia (com sorriso benevolente).

Ariane: - Bom dia (com sorriso benevolente).

Pignon: - Alguém quer café?

Bertrand: - Não, obrigada (sorrisos).

Ariane: - Não, obrigada (sorrisos).

Pignon segue em direção à porta para buscar café, mas se volta para Bertrand: - Vocês sabiam?

Bertrand: - Perdão?

Pignon: - Que vou ser demitido?

Bertrand: - Ah, eh, nada definido. Ouvi falar de uma reestruturação, mas nada certo.

Pignon olha com semblante fechado para ela e sai em busca do café. Após a saída dele, Bertrand comenta: - Coitado.

Ariane: - Sim, é triste.

\section{Análise}

$\mathrm{Na}$ sequência selecionada do filme notamos que ocorre inicialmente um processo de desconfirmação existencial, segundo a análise que podemos fazer a partir do pensamento de Laing (1973), quando o presidente da empresa desconsidera o aspecto emocional de Pignon e determina que a foto seja tirada sem a presença dele.

Cabe aqui uma colocação a partir dos aspectos presentes nas relações assimétricas que já vínhamos analisando neste trabalho. Falávamos anteriormente dos monólogos disfarçados. O presidente determina ao fotógrafo que bata a foto, mesmo sem ter sido resolvida a inclusão de Pignon no quadro. O fotógrafo contra-argumenta dizendo que "o de gravata vermelha" (Pignon) ainda está fora do quadro, mas o presidente retruca determinando mais uma vez que a foto seja tirada logo. Temos nessa situação um monólogo disfarçado que se caracteriza pela fala autoritária que não aceita contra-argumentação, mesmo quando estão envolvidos aspectos emocionais de um terceiro que foi excluído mediante uma ação autoritária. A fala do presidente se direciona ao fotógrafo, porém também inclui como destinatário a Pignon, que deve agir de modo a facilitar ao fotógrafo o cumprimento da determinação de bater logo a foto. 
O terceiro excluído no processo relacional está sendo incluído na conversa porque o autoritarismo precisa que a sua própria vontade seja cumprida.

Na cena do banheiro temos uma situação típica de ouvinte não ratificado, pois a presença de Pignon não havia sido detectada pelo chefe de pessoal e pelo fotógrafo. Lembramos o quanto é comum que as informações consideradas confidenciais circulem no ambiente organizacional. Nesse ambiente existem habitualmente mensagens que não devem chegar ao conhecimento de um indivíduo ou um grupo de indivíduos, mas os seus temas são conversados entre pessoas que os conhecem ou precisam passar a conhecê-los. Deste modo, muitos assuntos confidenciais passam a circular, embora nessas ocasiões sejam incluídas ressalvas de que são confidenciais. Isso faz-nos lembrar uma velha máxima que diz: "Se isso fosse mesmo um segredo não o teriam contado a mim".

Uma consequência desse tipo de circulação de informações é que as pessoas sabem que sempre há temas que são tratados em sigilo e, dentro de um grupo seleto de detentores de poder. Em decorrência, o sistema perde a sua confiabilidade. Na medida em que fico sabendo hoje de algo que envolve outras pessoas, pode ser que alguém saiba algo que me envolve e que eu não fico sabendo. Brandt e Gil (2007) apresentaram a análise a respeito desse tema a partir de conteúdos manifestados nos mesmos grupos de supervisores a que vimos nos referindo. Foram situações em que esses supervisores negaram conhecer algo que sabiam, ao serem questionados por subordinados e manifestaram, nos grupos de pesquisa, o incômodo provocado nessas ocasiões, para eles e para os subordinados.

Quando Pignon pergunta à sua chefa, a Srta. Bertrand, se ela sabia que ele seria demitido, temos um "festival" de comportamentos não-verbais que permitem confirmar a síntese dos estudos da comunicação não-verbal apresentada por Corraze (1982), mencionada anteriormente.

O centro da cena envolvendo esse diálogo ocupa dez segundos. Nesse tempo a Srta. Bertrand altera o ricto dos lábios e, em seguida, pisca os olhos nove vezes, movimenta a cabeça da esquerda para a direita e vice-versa oito vezes e no sentido vertical duas vezes, arqueia as sobrancelhas duas vezes, abre os olhos exageradamente duas vezes e engole em seco uma vez.

Esse conjunto de movimentos estabelece uma comunicação não-verbal que sugere que ela foi "pega na mentira". Ela nega que a demissão está definida, embora saiba que é verdade; a sua fala apresenta-se evasiva, mas esse conjunto de movimentos faciais e dos olhos evidencia a incoerência entre o verbal e o não-verbal.

A Srta. Bertrand não consegue assumir perante Pignon o conhecimento do destino desagradável que estava previsto para ele. Como visto em outra parte deste trabalho, a Srta. Bertrand não quer ameaçar a face de Pignon e também quer proteger a própria face.

Essa situação demonstra a razão de ser de muitas dificuldades dos profissionais que ocupam cargos de comando. Detectamos nos grupos de pesquisa de Brandt e Oliveira (no prelo) que esses profissionais têm dificuldade em abordar certos temas com as suas equipes devido aos diversos fatores que são próprios das organizações, que interferem em sua liberdade de atuação, em sua autonomia. Trata-se de assuntos que devem permanecer encobertos. Estão submetidos ao segredo ou sigilo porque envolvem, por exemplo, aspectos estratégicos, éticos, morais, de injustiças, de favorecimentos ou porque afetariam o clima organizacional se fossem conhecidos antes do momento apropriado.

São comuns as ocorrências envolvendo a relação entre o trabalhador e a organização do trabalho em que a decisão de contar ou negar algo se torna crucial para o líder formal. As más notícias são naturalmente desagradáveis, mas, contar que uma pessoa será demitida em trinta dias será adequado ou não para o ambiente e para o trabalhador? Por outro lado, é justo não contar? O problema estará no conflito íntimo desse líder quanto a revelar ou não informações sobre uma demissão, ou estará em sua dificuldade para abordar a forma e a razão 
de ser da decisão, ou ainda, estará na dificuldade em dar notícias ruins para uma pessoa? A pergunta que deve ser respondida é quanto ao fato em si, ou quanto às razões que levam ao fato? Ou quanto às dificuldades nas relações em que fica difícil dizer certas coisas?

Envolvidos em dilemas quanto à propriedade de comunicar ou não alguma coisa, os profissionais que estão no comando de equipes acabam tendo que negar algo que eles e também muita gente sabem; ao mesmo tempo, devem usar discursos que são contrários aos seus próprios valores. Quando lembram essas situações, os participantes dos grupos de pesquisa que analisamos demonstram frustração e impotência e manifestam esperar dos coordenadores desses grupos de pesquisa que eles lhes ensinem estratégias que deem conta dessas situações.

Os líderes também relatam o incômodo quanto a ter que lidar com notícias que incomodam. Manifestam seu desagrado quanto a terem que se envolver em problemas provocados por funcionários. Isso porque o dia-a-dia deveria ter menos problemas para que pudessem manter o adequado equilíbrio emocional.

Trazemos um caso que nos foi relatado por uma aluna durante a supervisão de estágio em Psicologia Organizacional. Contou essa moça que certa vez informou ao seu patrão que iria em breve deixar seu emprego na loja deste porque estava participando de um processo de seleção para uma corporação. Disse-lhe que estava informando previamente porque tinha uma relação de confiança com ele e não queria ficar inventando estórias para faltas ou atrasos em decorrência desse processo seletivo. Entretanto, passaram-se aproximados 60 dias até que esse processo de seleção fosse concluído e ela fosse finalmente convocada para a admissão. Nesse meio tempo, o ambiente entre essa moça e o patrão, bem como entre ela e os demais empregados dessa loja, ficou desagradável, "frio". Quando ela, finalmente, comunicou que sairia imediatamente, seu patrão lhe disse: "Nunca mais faça isso"! Ela então perguntou: "O quê"? E o patrão lhe respondeu: "Avisar que vai embora. Se você precisava sair mais cedo ou faltar, era melhor inventar qualquer coisa, mas não dizer que ia nos deixar".

Esse caso nos fala de algo relevante: que a informação, embora importante, pode ser prejudicial quando as pessoas não conseguem lidar adequadamente com ela. Parte representativa das pessoas prefere não ter que enfrentar os fatos que incomodam; preferem não saber algo que possa incomodar. O que iria incomodar nesse caso? Ter que conviver diariamente com uma pessoa que se tornara não-confiável porque iria abandonar o emprego. Retornando ao filme que analisamos, fica evidente que a Srta. Bertrand, chefe de Pignon, teria dificuldade em lidar diariamente com ele, caso ele ficasse sabendo que seria demitido daí a algum tempo.

Esse trecho do filme envolvendo a conversa entre a Srta. Bertrand e Pignon também ilustra como fica difícil aos líderes formais manterem coerência em suas conversações com subordinados. Isso explica o porquê de ser tão difícil liderar nas organizações. Como liderar se nas horas difíceis o profissional que deveria liderar é visto como incoerente, ou melhor, nãoconfiável?

\section{Considerações finais}

As pesquisas realizadas com o objetivo de analisar a conversa têm algo relevante a contribuir com a pesquisa das relações assimétricas no trabalho que vimos realizando com grupos de supervisores. As duas abordagens, analisadas em conjunto, podem fundamentar o aprofundamento dos estudos sobre liderança. 
Efetivamente, a partir das cenas de filme cuja análise apresentamos que são emblemáticas de situações que pertencem ao cotidiano do ambiente de trabalho organizado, temos a visão ampliada sobre fatores que afetam as conversas entre chefes e subordinados.

Em diversas situações as conversas precisam subordinar-se ao campo estratégico, o que implica em negar, disfarçar, falsear a verdade. Entretanto, nesses casos, o interlocutor que tem algo a esconder pode deixar transparecer que está escondendo. Ele pode ser "pego na mentira". Também estão presentes manifestações de prepotência das figuras de autoridade que não se mostram dispostas a investir em relações humanas.

Lembramos ainda, que nesse ambiente circulam segredos que não são contidos, cujos conteúdos chegam deturpados ou mesmo integrais às pessoas que não deveriam deles tomar conhecimento. Portanto, o chefe pode ser questionado sobre algo que deve negar. Existem também situações em que ele deve assumir certas posições sem conseguir expor os fatos ou expectativas que as justificam, pois teme dizer verdades que incomodam Também existem situações em que esse chefe de equipe não se sente confiante para assumir que desconhece um assunto ou uma decisão, pois teme aparentar insuficiência de poder.

Em todos esses casos, quando ele participa de situações que impliquem em conversar com subordinados, poderá ter que defender posições usando estratégias que não são facilmente dissimuláveis. Como disfarçar as manifestações não-verbais que irrompem sinalizando aos interlocutores que algo presente nessas conversas está indicando a existência de ambiguidades ou conteúdos conflitantes com outras informações? De que algo está a dizer que não se pode confiar no que é dito? Deparamos nos grupos de pesquisa a que nos referimos anteriormente, com relatos de situações nas quais esses profissionais tiveram que negar algo e ainda, muitas vezes, "criar" informações que pudessem ser assimiláveis pelos subordinados.

As manifestações não-verbais constituem parte natural das conversas. Existem ainda muitas regras de polidez, que também são necessárias nas conversas como forma de facilitar a recepção do outro, dando-lhe acolhimento ou aceitação. É conveniente, nas situações sociais, que a resposta a uma pergunta do tipo "Como vai?" seja respondida com a frase "Tudo bem, obrigado", mesmo que não esteja tudo bem e que ocorram manifestações não-verbais que indiquem que algo não anda bem. A resposta poderá ser diferente, mais de acordo com dados de realidade, se a situação social for de um encontro de pessoas que permita ou justifique uma resposta esclarecedora. Ou seja, no consultório médico a resposta será outra e em uma relação íntima podemos ter possibilidades diversas. E no trabalho organizado as respostas precisam adequar-se às condições que são próprias às relações assimétricas.

Outro ponto que devemos considerar nestas reflexões refere-se à disponibilidade do interlocutor para dedicar-se à conversação que está ocorrendo. Rodrigues e Silva (2006) tecem importantes considerações sobre esse tema a partir de suas pesquisas envolvendo cenas de conversações nas quais observaram a habilidade social denominada "ouvir ativo". Um real interesse na interlocução precisa ser manifestado pelos sujeitos envolvidos e esse interesse é demonstrado nos campos verbal e não-verbal.

Entretanto, quando estamos no ambiente do trabalho organizado, surgem outros fatores que precisam ser considerados na análise da conversação. A situação social fica impregnada de expectativas quando é perceptível algum risco para a permanência do interlocutor no emprego ou no cargo que ocupa. A carga emocional suportada quando há risco, coloca os interlocutores em posição de alerta, induzindo-os a atuar e a aplicar modos conversacionais que se distanciam daqueles que são aplicados em uma conversa de tipo despretensiosa. Sentimentos afloram afetando o campo não-verbal e mesmo o verbal, interferindo na relação estabelecida entre os interlocutores. Trata-se de mecanismos psíquicos e comunicativos disparados em situações para as quais os interlocutores não estão conseguindo sustentar posições e que provocam as reações que eles tendem a adotar quando se sentem ameaçados. E pode ocorrer com uma das partes ou ambas. 


\section{Referências}

Balint, M. (2005). O médico, seu paciente e a doença (título original: The doctor, the patient and his illness, 1957, trad. de Roberto de Oliveira Musachio, $2^{\underline{a}}$ ed.). São Paulo: Atheneu.

Brandt, J. A. (2006). A problemática da mudança e as relações entre os homens nas organizações de trabalho - um velho estudo de caso com uma nova análise. Dissertação de Mestrado, Instituto de Psicologia, Universidade de São Paulo, São Paulo.

Brandt, J. A. \& Gil, L. G. (2007). A negação e o desconhecido nas relações do supervisor com sua equipe: como fica a função de liderar? Mesa-redonda intitulada "Os vínculos no trabalho e os aspectos institucionais intervenientes", In Anais de resumo e de trabalhos completos do XIV Encontro Nacional da ABRAPSO. Rio de Janeiro, RJ.

Brandt, J A. \& Oliveira, I. C. (no prelo). Análise das relações do chefe com sua equipe no trabalho organizado. Psicologia USP.

Brown, P. \& Levinson, S. (1978). Politeness: some universals in language usage. In E. Goody, Questions and politeness: strategies in social interaction. Cambridge: Cambridge University Press.

Carducci, B. J. (2002). Timidez. São Paulo: Alegro.

Coulthard, M. (1997). An introduction to discourse analysis. Essex: Longman.

Corraze, J. (1982). As comunicações não-verbais. Rio de Janeiro: Zahar.

Enriquez, E. (1997). A Organização em análise. Petrópolis: Vozes.

Enriquez, E. (1991). Da Horda ao Estado: Psicanálise do vínculo social (2ª ed.). Rio de Janeiro: Zahar.

Giannetti, E. (2005). Autoengano. São Paulo: Cia. das Letras.

Goffman, E. (1983). A representação do eu na vida cotidiana. Petrópolis: Vozes.

Goffman, E. (2002). A situação negligenciada. In B. T. Ribeiro \& P. M. Garcez (Orgs.), Sociolinguística Interacional. (pp. 13-20). São Paulo: Loyola.

Kaës, R. (1997). O grupo e o sujeito do grupo: elementos para uma teoria psicanalítica do grupo. São Paulo: Casa do Psicólogo.

Kerbrat-Orecchioni, C. (2006). Análise da conversação. São Paulo: Parábola.

Knapp, M. L. \& Hall, A. J. (1999). Os efeitos do ambiente na comunicação humana. In M. L. Knapp \& A. J. Hall, Comunicação não-verbal na interação humana. São Paulo: JSN.

Laing, R. D. (1973). O eu dividido: estudo existencial da sanidade e da loucura. São Paulo: Vozes.

Malvezzi, S. (1999). Psicologia organizacional: da administração científica à globalização, uma história de desafios. In C. G. Machado, M. Melo, V. Franco \& N. Santos (Orgs.), Interfaces da psicologia. Actas do Congresso Internacional "Interfaces da Psicologia" (vol. 2, pp. 313-326). Évora: Universidade de Évora.

Marcuschi, L. A. (2006). Análise da conversação. São Paulo: Ática.

Philips, S. U. (2002). Algumas fontes de variação cultural na ordenação da fala. In B. T. Ribeiro \& P. M. Garcez (Orgs.), Sociolinguística interacional (pp.21-43). São Paulo:Loyola.

Ribeiro, B. T. \& Garcez, P. M. (2002). Sociolinguística interacional. São Paulo:Loyola.

Rodrigues, A. G. \& Silva, A. A. (2006). O ouvir ativo: uma habilidade social esquecida. In R. R. Starling \& K. A. Carvalho. (Orgs.), Ciência do comportamento: conhecer e avançar (vol. 5, pp. 66-77). Santo André: Esetec.

Smith, D. L. (2006). Por que mentimos? Entrevista concedida à Revista Veja em 18 outubro 2006.

Smith, D. L. (2005). Sussurros conspiradores e operações secretas. In D. L. Smith (Org.), Por que mentimos? Os fundamentos biológicos e psicológicos da mentira. São Paulo: Campus.

Veber, F. (2005). O Closet. DVD. Coprodução de Le Studio Canal + Gaumont Buena Vista International EFVE Films Production. Edição original de 2001.Warner Bros. Entertainment. 85 minutos. (Título original em francês: Le Placard) 
Watts, R., Ide de S. \& Ehlich, K. (2005). Linguistic politeness research: quo vadis? Politness in Language in retrospect. In Politeness in language: studies in its history, theory and practice $\left(2^{\text {nd }}\right.$ revised and expanded edition). Berlin: Mouton de Gruyter.

\section{Endereço para correspondência}

juabran@terra.com.br, ailton@uol.com.br

Recebido em: 04/09/2008

Revisado em: 25/11/2008

Aprovado em: 10/12/2008 